\title{
A compilation of and typology for abundance-, phylogenetic- and functional-based diversity metrics
}

\author{
Samuel M. Scheiner \\ Division of Environmental Biology, National Science Foundation \\ 2415 Eisenhower Ave., Alexandria, VA 22314 USA \\ E-mail: sscheine@nsf.gov
}

\begin{abstract}
Ecologists are faced with an over-abundance of ways to measure biodiversity. In this paper, I provide a compilation of and guide through this ticket of diversity metrics. I present a typology for diversity metrics that encompasses the three commonly considered categories of information: abundance, phylogenetic relationships, and traits (i.e., function). I update and expand previous summaries of diversity metrics. The formulas of those 117 metrics are presented in a standard notation and format that makes it easy to see the mathematical similarities and differences among the metrics. Finally, I propose a standard set of symbols for many of the metrics that makes their properties immediately obvious. This compilation will make it easier for researchers to identify the metric(s) most suited to their needs and will help guide future metric development.
\end{abstract}




\section{Introduction}

Ecologists are faced with an over-abundance of ways to measure biodiversity (Peet 1974, Magurran 1988, Magurran and McGill 2011). Navigating that thicket can be challenging, often resulting in the use of metrics because they are commonly found in the literature, rather than because a given metric is the one most suited to the question being posed. In addition, nearly all commonly used metrics are composites; they consist of more than one component of biodiversity. This composite nature is often hidden by the way the metrics are described or calculated, so determining the correct metric for a given task is not always obvious.

The goals of this paper are fourfold: The first goal is to provide a typology for diversity metrics that encompasses the three commonly considered categories of information: abundancc, phylogenies, and traits (i.e., function). This typology leans heavily on that of Tucker et al. (2017) for phylogenetic diversity metrics, but goes beyond it to further refine their schema and also apply it to trait-based metrics. The second goal is to update the summary of phylogenetic-based diversity metrics of Tucker et al. (2017) and the summary of trait-based diversity metrics of Weiher (2011) as well as proposing new metrics that flow from the new typology. The third goal is to put all of the formulas for these diversity metrics in a standard notation and format that makes it easy to see the mathematical similarities and differences among the metrics. The fourth goal is to propose a standard set of symbols for many of the metrics that makes their properties immediately obvious. The following sections address each of these goals in turn. 


\section{A typology for diversity metrics}

Biodiversity consists of a variety of types of information that can be separated and recombined into a myriad of diversity metrics. My proposed typology begins by identifying the basic information components (four types of information, two properties of that information, and three methods for measuring that information), defines a set of elemental diversity metrics from those components, and then shows how those elements can be combined to produce both familiar diversity metrics and new metrics that are analogous to existing metrics using different elements. I start with the four basic types of information: identity, abundance, phylogenetic relationships, and traits. Note that the last item is "traits" rather than "functions" or "functional traits." While we conventionally speak of "functional diversity," the "function" part comes from assuming that the traits included in an analysis are the most relevant for the ecological and evolutionary processes that determine the diversity of a community or the effects of those species on ecosystem processes. That assumption is not unwarranted. In general, researchers have an intuitive understanding of which traits are important. That link to processes, however, is almost never actually measured. Rather, we just have the trait measurements. Thus, throughout the rest of this paper I will use the phrase "trait diversity" for the concept that is typically called "functional diversity."

The four types of information differ in that identity and absolute abundance are aspects of a species that are not mathematically dependent on any other species in an assenblage. In contrast, phylogenetic and trait relationships are aspects that can only be measured relative to other species. They are typically undefined for a monotypic assemblage. Additionally, three of those types of information - abundance, phylogeny, traits - evince two properties: magnitude and variability that each can vary independently and which are labeled as follows (Scheiner et al. 2017a):

\begin{tabular}{|l|l|l|}
\hline Data type & Magnitude & Variability \\
\hline Abundance & Numbers & Evenness \\
\hline Phylogeny & Divergence & Regularity \\
\hline Trait & Dispersion & Equability \\
\hline
\end{tabular}


Magnitude is how much each of the species in an assemblage manifests some property. For abundance, magnitude (numbers) is typically the total number of individuals of a particular species, although it can be measured in a variety of other ways such as frequency of occurrence, biomass, or geographic range. For phylogeny, magnitude (divergence) is the amount of evolutionary differentiation of a particular species from other species (Figure 1A). For traits, magnitude (dispersion) is the amount of difference in trait values of a particular species from other species (Figure 1B). Variability quantifies the extent to which magnitudes differ among those species. For abundance, variability (evenness) is the similarity in the (relative) number of individuals of each species. For phylogeny, variability (regularity) is the extent to which species are equally divergent. For traits, variability (equability) is the extent to which species are equally different from each other in trait values.
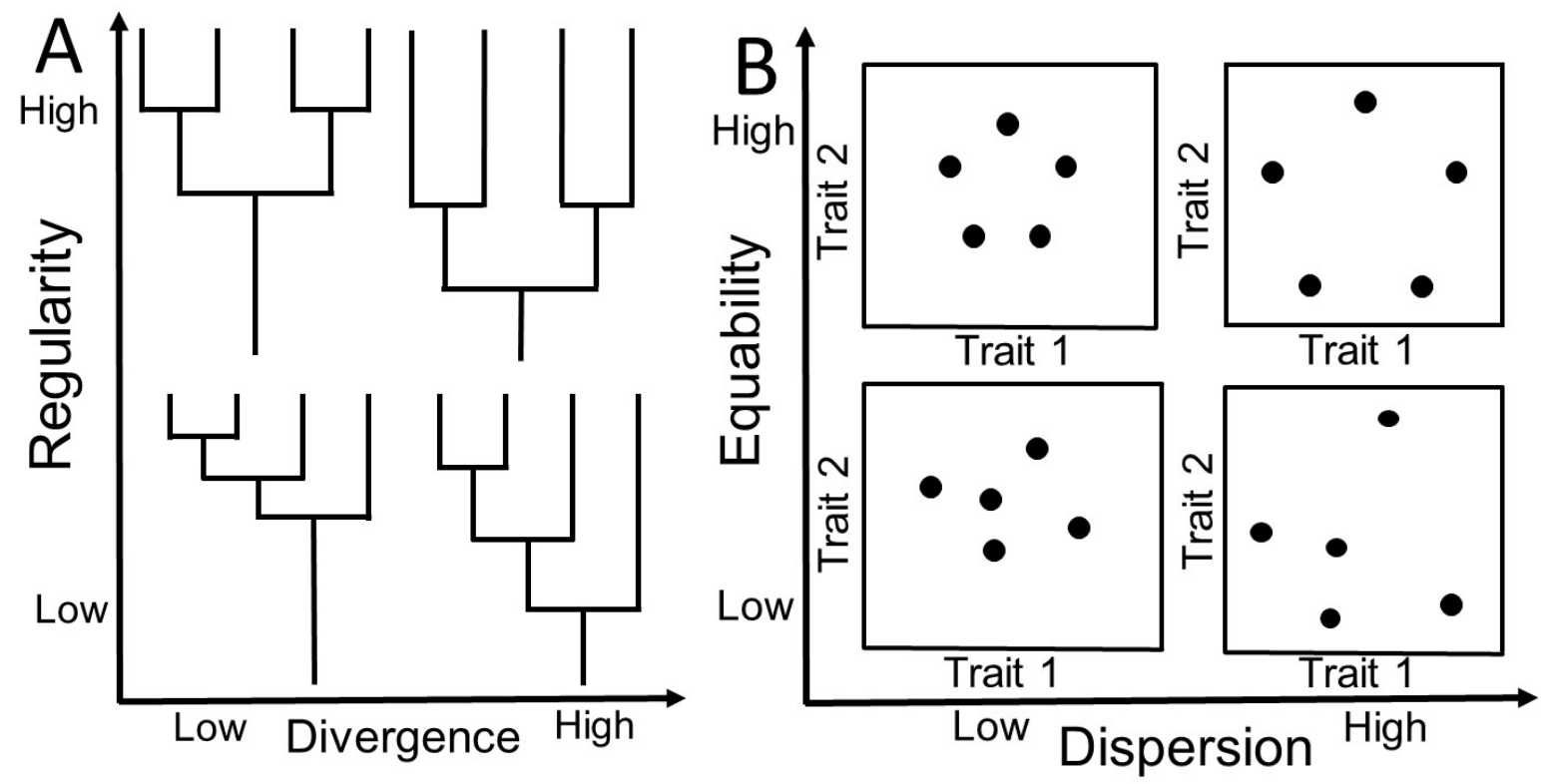

Figure 1. (A) Four phylogenies showing how magnitude (divergence) and variability (regularity) can vary independently. A phylogeny with higher divergences has longer branch lengths towards the tips. A phylogeny with higher regularity has more symmetrical or similar length branches. (B) Four assemblages showing how magnitude (dispersion) and variability (equability) can vary independently. Species with higher dispersions have greater distances among the species in trait space. Species with higher equability have more similar distances among the species. 
Because both phylogenetic and trait information are determined relative to other species, there are three methods for measuring these properties: total, pairwise, and nearest-neighbor. For phylogenetic information, total metrics are based on mseasures of the total branch lengths from root to tip for each species. Most commonly, shared branch lengths are divided by what are called "fair proportions" (Isaac et al. 2007) although other divisions are possible (Cadotte and Jonathan Davies 2010). Both pairwise and nearest-neighbor metrics are based on the lengths of branches from one tip of the phylogeny to another, with the former comprising all pairwise lengths and the latter just the smallest length. They both differ from total metrics in that they do not include any shared branches. For example, in Figure 1A, the single root branch in each of the phylogenies would not be included in any pairwise or nearest-neighbor metrics. Thus, for total metrics the sum of the values for each species always equal the total branch length; that equivalence does not hold for pairwise or nearest-neighbor metrics.

For trait information, total metrics are based on the mean distance of each species from all others, pairwise metrics are based on the individual pairs of distances between each species, and nearest-neighbor metrics are based on just the smallest distance for each species. (Analogous quantities can be computed if the traits are categorical, rather than continuous.) Both total and pairwise metrics have the same sums and overall means so that magnitude metrics do not differ; they do differ for variability metrics. Trait diversity metrics can also be separated based on two concepts: uniqueness and combinatorics (see Figure 1 of Scheiner et al. 2017b). For the uniqueness concept, if data are categorical, trait diversity is greatest when each species in an assemblage has a unique set of trait attributes; if the data are continuous, diversity is greatest when the species are as far apart from each other as possible. For the combinatorics concept, if data are categorical, diversity is greatest when an assemblage contains species that have every possible combination of trait attributes; if the data are continuous, diversity is greatest when dispersion is as compact as possible while equalizing the minimum distances between species.

Leinster and Cobbold (2012) provide a list of preferred properties for diversity metrics based on consideration of effective numbers, modularity, replication, symmetry, the effect of absent species, the effect of identical species, monotonicity, how metrics simplify when abundance, phylogeny, or trait values are not included (naive model), and the range of the metric. Some of those properties (e.g., effective numbers, data range) hold only for metrics that combine species richness with other elements. So not all diversity metrics satisfy their criteria. However, their 
criteria are useful for examining the properties of various metrics. The list of metrics presented in this paper is meant to be comprehensive rather than prescriptive. I take no position on whether all of the properties of Leinster and Cobbold are required for any given metric.

\section{A summary of diversity metrics}

I begin my summary of diversity metrics by defining 14 basic elements, the 13 cells in Table 1 plus identity information. The most common type of identity is "species" but other units are possible (e.g., genus, genotype). When the units are species, then identity diversity equals species richness (S). Those 14 basic elements can be measured in more than one way (e.g., the three different metrics for equability based on nearest-neighbor distances). After combining those elements in various ways, the result is 117 different metrics. That number does not include all metrics already in the literature, although it does include the commonly used ones, as well as many new metrics.

At this point, you may well ask yourself: "Does ecology really need this many ways to measure biodiversity?" My purpose here is not to overwhelm the reader. Quite the opposite. My purpose is to show that all of these metrics are simply combinations of the 14 basic elements, and even those basic elements reduce to just three categories (four types of information, two properties, and three measurement methods).

Organizing the metrics in this fashion accomplishes three goals. First, it identifies which metrics are based on the same types of information, properties, or measurement methods. If you wish to compare phylogenetic and trait diversity for a set of species, it does not make sense to compare a measure of pairwise divergence with a measure of nearest-neigbor equability. The tables below make it easy to identify comparable metrics.

Second, it helps distinguish between different types of combinations of elements, for example, a measure of abundance-weighted phylogenetic diversity $\left[{ }^{9} \mathrm{DA}\left(\mathrm{P}_{\mathrm{T}}\right)\right.$, which combines elements of identity, numbers, and total regularity] as compared to a measure of phylogenetic-weighted abundance diversity $\left[{ }^{\mathrm{q}} \mathrm{DP}_{\mathrm{T}}(\mathrm{A})\right.$, which combines elements of identity, evenness, and total divergence] (see table A5). Recognizing that these two metrics combine different basic elements prevents confusion or inappropriate comparisons, especially across studies done by different researchers. 
Third, it identifies "missing" metrics. Imagine Tables 1-5 without any of the metrics in italic or bold font. That is how I began this compilation. The metrics in italic are ones that are implied by previously published metrics. The most obvious are measures of regularity or equability that are derived from Hill-based diversity metrics by dividiing by $\mathrm{S}\left(\mathrm{e} . \mathrm{g} .,{ }^{\mathrm{q}} \mathrm{E}\left(\mathrm{T}_{\mathrm{T}}\right)\right.$, Table 1$)$. The metrics in bold are ones that were suggested by analogy with existing metrics. For example, metrics had been proposed for divergence based on total and pairwise measures and for regularity based on total measures (Table 2). Those measures suggested the possibility of additional metrics of nearestneighbor divergence, pairwise regularity, and nearest-neighbor regularity based on simple substitutions or modifications of existing formulas. Once I began this process, it became straightforward to continue until all of the cells in Tables 1-5 contained at least one metric. Even if a cell already contained a metric, others were added if they were based on combinations of basic elements that were not previously considered, or if based on different concepts of magnitude or variability. For the most part, the metrics are as originally presented. My only systematic deviation from that practice is that all of the variance-based metrics of Tucker et al. (2017) were converted to standard deviations so as to make units comparable between magnitude and variability (Table A3).

Fourth, my typology makes it easier for researchers to develop new metrics if none of the existing metrics are best suited for the task at hand. Additional metric might be implied by analogy with those presented here. Or, the basic elements might be combined in yet new ways. Or different types of basic elements might be developed, for example other ways of measuring variability.

The effective number of species are the number of species that an assemblage would contain if all species had equal abundances, divergences, or dispersions (Jost 2006). They are obtained by multiplying a measure of evenness, regularity, or equability by species richness (Jost 2010). The metrics in Tables 2 and 5 are the only ones that might represent effective numbers. Not all of those metrics result in measures of the effective number of species, however. Only if the other element(s) of the metric have a range of $(0,1]$ will the resulting combination have a range of $(0, S]$. So species richness (identity) is a necessary, but not sufficient, ingredient for a measure of effective numbers. 
Table 1. Metrics of thirteen of the basic elements (plus identity). Metrics in this and subsequent tables in bold are newly proposed; metrics in italics are implied by previously proposed metrics. See Table A1 for the formulas for each metric, along with the name, alternative symbols, the quantities that each measure, and the source.

\begin{tabular}{|c|c|c|c|c|c|c|}
\hline & \multicolumn{3}{|c|}{ Magnitude } & \multicolumn{3}{|c|}{ Variability } \\
\hline Data type & Total & Pairwise & Nearest & Total & Pairwise & Nearest \\
\hline Abundance & $\mathrm{M}(\mathrm{A})$ & --- & --- & ${ }^{\mathrm{q}} \mathrm{E}(\mathrm{A})$ & --- & --- \\
\hline Phylogeny & $\begin{array}{l}\mathrm{M}\left(\mathrm{P}_{\mathrm{T}}\right) \\
\mathrm{AvPD}\end{array}$ & $\begin{array}{l}\mathrm{M}\left(\mathrm{P}_{\mathrm{P}}\right) \\
\mathrm{J} \text { PSV }\end{array}$ & $\mathrm{M}\left(\mathrm{P}_{\mathrm{N}}\right)$ & $\begin{array}{l}{ }^{q} E\left(P_{T}\right) \\
\mathbf{C}\left(\mathbf{P}_{\mathbf{T}}\right)\end{array}$ & $\begin{array}{l}{ }^{{ }^{q}} \mathbf{E}\left(P_{P}\right) \\
\mathbf{C}\left(P_{P}\right)\end{array}$ & $\begin{array}{c}{ }^{\mathrm{q}} \mathbf{E}\left(\mathbf{P}_{\mathrm{N}}\right) \\
\mathbf{C}\left(\mathbf{P}_{\mathrm{N}}\right)\end{array}$ \\
\hline Trait & & & $\mathrm{M}\left(\mathrm{T}_{\mathrm{N}}\right)$ & ${ }^{q} E\left(T_{T}\right)$ & ${ }^{\mathrm{q}} \mathrm{E}\left(\mathrm{T}_{\mathrm{P}}\right)$ & $\begin{array}{c}{ }^{q} E\left(T_{N}\right) \\
\mathbf{C}\left(\mathbf{T}_{\mathrm{N}}\right) \\
\text { FNEve }\end{array}$ \\
\hline
\end{tabular}

Table 2. Metrics that combine species richness with one other basic element (see Table A2 for the formulas).

\begin{tabular}{|c|c|c|c|c|c|c|}
\hline & \multicolumn{3}{|c|}{ Magnitude } & \multicolumn{3}{c|}{ Variability } \\
\hline Data type & Total & Pairwise & Nearest & Total & Pairwise & Nearest \\
\hline Abundance & $\mathrm{N}$ & --- & --- & ${ }^{\mathrm{q}} \mathrm{D}(\mathrm{A})$ & --- & --- \\
\hline \multirow{2}{*}{ Phylogeny } & $\Sigma\left(\mathrm{P}_{\mathrm{T}}\right)$ & $\Sigma\left(\mathrm{P}_{\mathrm{P}}\right)$ & $\boldsymbol{\Sigma}\left(\mathbf{P}_{\mathrm{N}}\right)$ & ${ }^{\mathrm{q}} \mathrm{D}\left(\mathrm{P}_{\mathrm{T}}\right)$ & ${ }^{\mathbf{q}} \mathbf{D}\left(\mathbf{P}_{\mathbf{P}}\right)$ & ${ }^{\mathbf{q}} \mathbf{D}\left(\mathbf{P}_{\mathrm{N}}\right)$ \\
& $\mathrm{M}(\mathrm{PR})$ & $\mathrm{PSR}$ & & & & \\
\hline \multirow{2}{*}{ Trait } & $\begin{array}{c}\Sigma\left(\mathrm{T}_{\mathrm{T} / \mathrm{P}}\right) \\
\text { FRic }\end{array}$ & $\Sigma\left(\mathrm{T}_{\mathrm{T} / \mathrm{P}}\right)$ & $\begin{array}{c}\boldsymbol{\Sigma}\left(\mathbf{T}_{\mathrm{N}}\right) \\
\text { FD }\end{array}$ & ${ }^{\mathrm{q}} \mathrm{D}\left(\mathrm{T}_{\mathrm{T}}\right)$ & ${ }^{\mathrm{q}} \mathrm{D}\left(\mathrm{T}_{\mathrm{P}}\right)$ & ${ }^{\mathrm{q}} \mathrm{D}\left(\mathrm{T}_{\mathrm{N}}\right)$ \\
\hline
\end{tabular}

Table 3. Metrics that combine magnitude and variability of the same data type (see Table A3 for the formulas).

\begin{tabular}{|c|c|c|c|}
\hline Data type & Total & Pairwise & Nearest \\
\hline Phylogeny & $\sigma\left(P_{T}\right)$ & $\begin{array}{c}\sigma\left(P_{P}\right) \\
\sigma A\left(P_{P}\right)\end{array}$ & $\begin{array}{c}\sigma\left(P_{N}\right) \\
\sigma A\left(P_{N}\right)\end{array}$ \\
\hline Trait & $\boldsymbol{\sigma}\left(\mathbf{T}_{\mathbf{T}}\right)$ & $\begin{array}{c}{ }^{\mathrm{q}} \mathrm{DM}\left(\mathrm{T}_{\mathrm{P}}\right) \\
{ }^{\mathrm{q}} \mathrm{DMA}\left(\mathrm{T}_{\mathrm{P}}\right)\end{array}$ & $\sigma\left(\mathrm{T}_{\mathrm{N}}\right)$ \\
\hline
\end{tabular}


bioRxiv preprint doi: https://doi.org/10.1101/530782; this version posted February 8, 2019. The copyright holder for this preprint (which was not certified by peer review) is the author/funder. This article is a US Government work. It is not subject to copyright under 17 USC 105 and is also made available for use under a CCO license.

Table 4. Metrics that combine abundance with one other basic element involving phylogeny or traits (see Table A4 for the formulas).

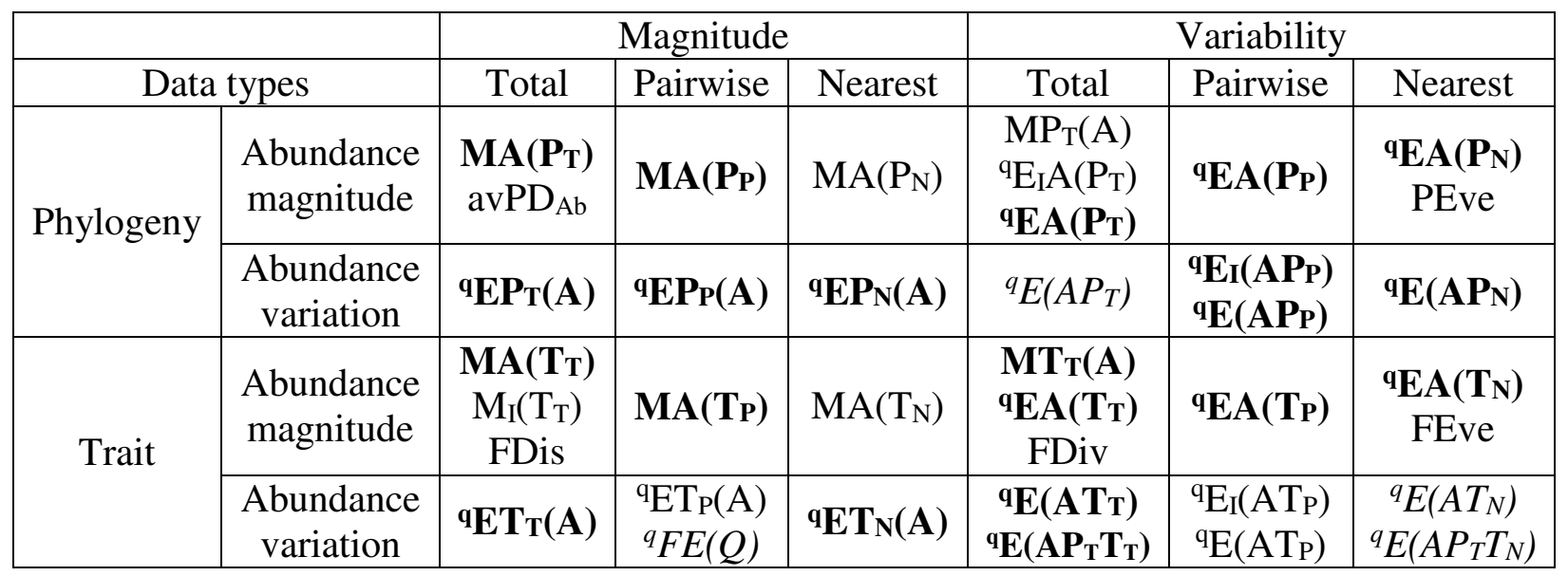

Table 5. Metrics that combine species richness and abundance with one or more other basic elements involving phylogeny or traits (see Table A5 for the formulas).

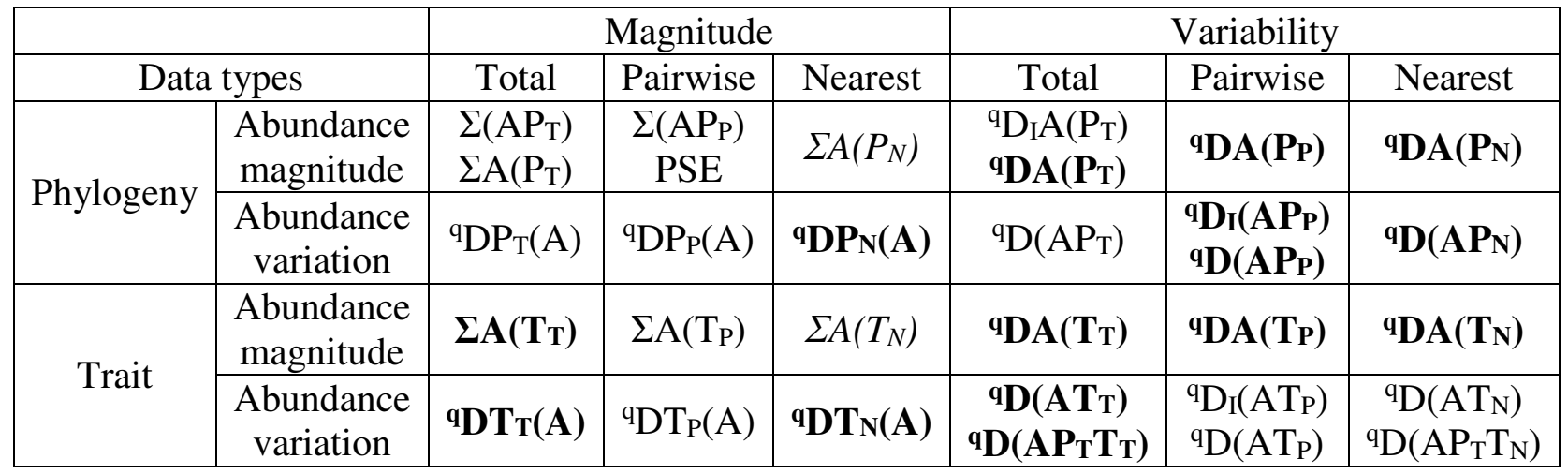




\section{Standardizing diversity metric formulas}

All of the formulas in the appendix use a consistent set of symbols for all parameters. Doing so avoids creating confusion by the use of the same symbol for different concepts (e.g., using " $d$ " for both branch length and trait-space distance). For the most part, the symbols used are those typically found in previous publications, except where the same symbol was being used for differen concepts. Where possible, subscripts are used to distinguish between related parameters (e.g., min for metrics involving nearest-neighbor divergences or distances). The formulas are also presented in as atomistic a fashion possible (e.g., denominators show full summations rather than a composite sum). Doing so makes it easy to see the components of each formula, avoids confusion, and limits the number of symbols needed. I urge other researchers to further this usage to make as clear as possible the relationship of any new metric to current metrics.

\section{A proposed set of symbols for diversity metrics}

I am proposing a consistent symbology for many of the diversity metrics. This system is designed to convey information about the content of the metric; that is, the symbol is more than just an arbitrary designation. The system is applied primarily to metrics that are based on Hill diversity (Hill 1973), but also those that rely on standard mathematical operations (averages, standard deviations, and coefficients of variation). I developed this system in assembling the metrics in this paper. Especially as new metrics were being described, I discovered that previous symbols, including ones in my own papers, were inadequate for creating a unique symbol for each metric. In addition, for some metrics there was no single, standard symbol. The proposed system conveys the three categories of information as follows:

1) Type of information: $\mathrm{A}=$ abundance, $\mathrm{P}=$ phylogenetics, $\mathrm{T}=$ traits

2) Property as determined by the mathematical function:

Magnitude: $\mathrm{M}=$ mean, $\Sigma=$ sum

Variability: $\sigma=$ standard deviation, $\mathrm{C}=$ coefficient of variation, $\mathrm{D}=$ Hill diversity, $\mathrm{E}=$ Hill evenness

For Hill functions, the superscript q = exponent (typically 0, 1, or 2)

For trait information, the subscript $\mathrm{I}=$ operation performed on individuals within species

3) Type of measurement for phylogenetic or trait information denoted as a subscript: $\mathrm{T}=$ total, $\mathrm{P}=$ pairwise, $\mathrm{N}=$ nearest-neighbor 
If the symbol for a type of information is inside the parenthesis of a function, the function is performed on that parameter. If the symbol is outside the parenthesis, that parameter is a weighting factor. For example, ${ }^{9} \mathrm{DT}_{\mathrm{P}}(\mathrm{A})$ is Hill diversity of abundance information weighted by pairwise trait information; ${ }^{\mathrm{q}} \mathrm{DA}\left(\mathrm{T}_{\mathrm{P}}\right)$ is Hill diversity of pairwise trait information weighted by abundance information; ${ }^{\mathrm{q}} \mathrm{D}\left(\mathrm{AT}_{\mathrm{P}}\right)$ is Hill diversity of both abundance and pairwise trait information. Not included here, because I do not list their formulas, are symbols designating ecological hierarchies ( $\alpha$-. $\beta$-, and $\gamma$-diversity). Those would be added as subscripts of the mathematical function.

I urge the use of a consistent set of symbols to make it easier for the reader to understand what metric is being used, especially if the formula for that metric is not given in the publication. I am well aware that getting authors to do so is difficult. In one case, one of my own metrics was used in a paper with a notation that differed from the one in my original publication. As my publication listed several different metrics, it was not obvious which one was being used. Editors and reviewers are critical for encouraging usage consistency.

\section{Concluding remarks}

I wish to be clear that in this paper I am not advocating the use of any specific metrics. Rather, my goal is to be as comprehensive as possible so that you can identify the metric(s) that are most appropriate for the question that you wish to address. This task is especially important for metrics that are composites of two or more elements, as it is not always obvious what elements are being combined. For example, is this metric measuring abundance diversity weighted by phylogenetic information, or phylogenetic diversity weighted by abundance information? Such identification ensures that comparisons among diversities measured with different types of information (e.g., phylogenetic and trait information) are done with metrics based on similar properties (e.g., both are based on nearest-neighbor data). Even more important, it points out that certain types of comparison are not informative. A correlation of Hill diversity metrics of phylogenetic and trait data is such a comparison. Both metrics include species richness as a component so that any correlation is (partially) based on a correlation of a parameter with itself. Instead, the correlation should be done using Hill evenness metrics, which do not contain overlapping elements. 
My compilation is incomplete in several regards. First, I have undoubtably left out some metrics despite my attempts to ferret them out. Second, there are other aspects of biodiversity that are not addressed here; my focus is exclusively on metrics relevant to species within communities. Nor does the compilation consider other types of measures, such as entropy (Jost 2006). Third, all of the formulas presented here assume no sampling bias. Bias-corrected formulas for some of the metrics can be found in (Colwell and Coddington 1994, Chao and Jost 2012, Chao et al. 2013, Chao et al. 2015) among other publications. Fourth, I do not deal with hierarchical data structures and metrics of $\alpha$-diversity (mean subsample) and $\beta$-diversity (among subsample). Again, formulas for hierarchical data structures for some of the metrics can be found in various other publications (e.g., Tuomisto 2010, Chao et al. 2012, Chiu et al. 2014, Pavoine et al. 2016, Scheiner et al. 2017b, Tucker et al. 2017, Podani et al. 2018). 


\section{Literature cited}

Barker, G. M. 2002. Phylogenetic diversity: a quantitative framework for measurement of priority and achievement in biodiversity conservation. Biological Journal of the Linnean Society 76:165-194.

Cadotte, M. W. and T. Jonathan Davies. 2010. Rarest of the rare: advances in combining evolutionary distinctiveness and scarcity to inform conservation at biogeographical scales. Diversity and Distributions 16:376-385.

Chao, A., C.-H. Chiu, and T. C. Hsieh. 2012. Proposing a resolution to debates on diversity partitioning. Ecology 93:2037-2051.

Chao, A., C.-H. Chiu, T. C. Hsieh, T. Davis, D. A. Nipperess, and D. P. Faith. 2015. Rarefaction and extrapolation of phylogenetic diversity. Methods in Ecology and Evolution 6:380-388.

Chao, A., C.-H. Chiu, and L. Jost. 2010. Phylogenetic diversity measures based on Hill numbers. Philosophical Transactions of the Royal Society London B 365:3599-3609.

Chao, A., N. J. Gotelli, T. C. Hsieh, E. L. Sander, K. H. Ma, R. K. Colwell, and A. M. Ellison. 2013. Rarefaction and extrapolation with Hill numbers: a framework for sampling and estimation in species diversity studies. Ecological Monographs 84:45-67.

Chao, A. and L. Jost. 2012. Coverage-based rarefaction and extrapolation: standardizing samples by completeness rather than size. Ecology 93:2533-2547.

Chiu, C.-H. and A. Chao. 2014. Distance-based functional diversity measures and their decomposition: a framework based on Hill numbers. PLoS ONE 9:e100014.

Chiu, C.-H., L. Jost, and A. Chao. 2014. Phylogenetic beta diversity, similarity, and differentiation measures based on Hill numbers. Ecological Monographs 84:21-44.

Clarke, K. R. and R. M. Warwick. 1998. Quantifying structural redundancy in ecological communities. Oecologia 113:278-289.

Clarke, K. R. and R. M. Warwick. 2001. A further biodiversity index applicable to species lists: variation in taxonomic distinctness. Marine Ecology Progress Series 216:265-278.

Colwell, R. K. and J. A. Coddington. 1994. Estimating terrestrial biodiversity through extrapolation. Philosophical Transactions of the Royal Society of London. Series B: Biological Sciences 345:101-118.

Cornwell, W. K., D. W. Schwilk, and D. D. Ackerly. 2006. A trait-based test for habitat filtering: convex hull volume. Ecology 87:1465-1471. 
Dehling, D. M., S. A. Fritz, r. T. Töpfe, M. Päckert, P. Estler, K. Böhning-Gaese, and M. Schleuning. 2014. Functional and phylogenetic diversity and assemblage structure of frugivorous birds along an elevational gradient in the tropical Andes. Ecography 37:10471055.

Faith, D. P. 1992. Conservation priorities and phylogenetic diversity. Biological Conservation 61:1-10.

Helmus, M. R., T. J. Bland, C. K. Williams, and A. R. Ives. 2007. Phylogenetic measures of biodiversity. American Naturalist 169:E68-E83.

Hill, M. O. 1973. Diversity and evenness: a unifying notation and its consequences. Ecology 54:427-432.

Isaac, N. J. B., S. T. Turvey, B. Collen, C. Waterman, and J. E. M. Baillie. 2007. Mammals on the EDGE: conservation priorities based on threat and phylogeny. PLoS ONE 2:e296.

Izsák, J. and L. Papp. 2000. A link between ecological diversity indices and measures of biodiversity. Ecological Modelling 130:151-156.

Jost, L. 2006. Entropy and diversity. Oikos 113:363-375.

Jost, L. 2010. The relation between evenness and diversity. Diversity 2:207-232.

Laliberté, E. and P. Legendre. 2010. A distance-based framework for measuring functional diversity from multiple traits. Ecology 91:299-305.

Leinster, T. and C. A. Cobbold. 2012. Measuring diversity: the importance of species similarity. Ecology 93: 477-489.

Magurran, A. and B. J. McGill. 2011. Biological Diversity. Oxford University Press, New York.

Magurran, A. E. 1988. Ecological Diversity and Its Measurement. Princeton University Press, Princeton, New Jersey, USA.

Pavoine, S., E. Marcon, and C. Ricotta. 2016. 'Equivalent numbers' for species, phylogenetic or functional diversity in a nested hierarchy of multiple scales. Methods in Ecology and Evolution 7:1152-1163.

Peet, R. K. 1974. The measurement of species diversity. Annual Review of Ecology and Systematics 5:285-307.

Petchey, O. L. and K. J. Gaston. 2002. Functional diversity (FD), species richness and community composition. Ecology Letters 5:402-411. 
Podani, J., S. Pavoine, and C. Ricotta. 2018. A generalized framework for analyzing taxonomic, phylogenetic, and functional community structure based on presence-absence data. Mathematics 6:250.

Presley, S. J., S. M. Scheiner, and M. R. Willig. 2014. Evaluation of an integrated framework for biodiversity with a new metric for functional dispersion. PLoS ONE 9:e105818.

Ricklefs, R. E. and J. Travis. 1980. A morphological approach to the study of avian community organization. The Auk 97:321-338.

Scheiner, S. M. 2012. A metric of biodiversity that integrates abundance, phylogeny, and function. Oikos 121:1191-1202.

Scheiner, S. M., E. Kosman, S. J. Presley, and M. R. Willig. 2017a. The components of biodiversity, with a particular focus on phylogenetic information. Ecology and Evolution 7:6444-6454.

Scheiner, S. M., E. Kosman, S. J. Presley, and M. R. Willig. 2017b. Decomposing functional diversity. Methods in Ecology and Evolution 8:809-820.

Tucker, C. M., M. W. Cadotte, S. B. Carvalho, T. J. Davies, S. Ferrier, S. A. Fritz, R. Grenyer, M. R. Helmus, L. S. Jin, A. O. Mooers, S. Pavoine, O. Purschke, D. W. Redding, D. F. Rosauer, M. Winter, and F. Mazel. 2017. A guide to phylogenetic metrics for conservation, community ecology and macroecology. Biological Reviews 92:698-715.

Tuomisto, H. 2010. A diversity of beta diversities: straightening up a concept gone awry. Part 1. Defining beta diversity as a function of alpha and gamma diversity. Ecography 33:2-22.

Vellend, M., W. K. Cornwell, K. Magnuson-Ford, and A. Ø. Mooers. 2011. Measuring phylogenetic diversity. Pages 194-207 in A. E. Magurran and B. J. McGill, editors. Biological Diversity. Oxford University Press, New York.

Villéger, S., N. W. H. Mason, and D. Mouillot. 2008. New multidimensional functional diversity indices for a multifaceted framework in functional ecology. Ecology 89:2290-2301.

Walker, B., A. Kinzig, and J. Langridge. 1999. Plant attribute diversity, resilience, and ecosystem function: the nature and significance of dominant and minor species. Ecosystems 2:95-113.

Webb, C. O., D. D. Ackerly, M. A. McPeek, and M. J. Donoghue. 2002. Phylogenies and community ecology. Annual Review of Ecology and Systematics 33:475-505.

Weiher, E. 2011. A primer of trait and functional diversity. Pages 175-193 in A. E. Magurran and B. J. McGill, editors. Biological Diversity. Oxford University Press, New York. 


\section{Appendix}

In all tables, previously used symbols are given in brackets. The source given is the first occurrence of a metric in the literature, even when that metric was subsequently, independently derived. Symbols use in the tables are as follows:

$S:$ the number of species

$n_{i}$ : the number of individuals of species $i$

$N$ : the total number of individuals in an assemblage

$T$ : the time-depth of a cladogram

$B$ : the number of branches on a cladogram

$N_{b}$ : the total number of individuals of all species that share the $b$ th branch segment on a cladogram

$L_{b}$ : the length of the $b$ th branch segment on a cladogram

$L_{i b}$ : the proportional share of the $b$ th branch segment of species $i$

$L_{i}$ : the total proportional branch length share of species $i$

$\varphi_{i j}$ : the total branch length between species $i$ and $j$

$\varphi_{i \text { min }}$ : the shortest branch length between species $i$ and all other species

$\psi_{i j}$ : the amount of unshared branch length between species $i$ and $j,=1-\left[c_{i j} / \sqrt{ }\left(c_{i i} c_{j j}\right)\right]$, where $c_{i i}$ $\left(c_{j j}\right)=$ the sum of the branch lengths for species $i(j)$, and $c_{i j}$ is the sum of the branch lengths from the root to the most recent common ancestor of species $i$ and $j$. [ Note that $\psi_{i j}=\varphi_{i j}$ for the alternative definition, $=0.5\left(c_{i i}+c_{j j}-c_{i j}\right)$.]

$d_{i}$ : the mean standardized trait distance of species $i$ and all other species

$d_{i j}$ : the standardized trait-space distance between species $i$ and $j$

$d_{i \text { min }}$ : the smallest standardized trait-space distance between species $i$ and all other species

$d_{k l}$ : the standardized trait-space distance between individuals $k$ and $l$ ignoring species identity

$\delta_{i}$ : the distance of species $i$ from the abundance-weighted centroid of the species trait-space distribution

$\Delta d$ : the sum of abundance-weighted deviances from the centroid of the trait-space convex hull

$\Delta|d|$ : the sum of absolute abundance-weighted deviances from the centroid of the trait-space convex hull

$\overline{d G}$ : the mean distance from the centroid of the trait-space convex hull

$\mu_{l \text { min }}$ : the length of the $l$ th branch connecting species $i$ and $j$ of a minimum spanning tree constructed from phylogenetic or trait distances

q: the exponent of the Hill function 
Table A1. Metrics of fourteen of basic elements

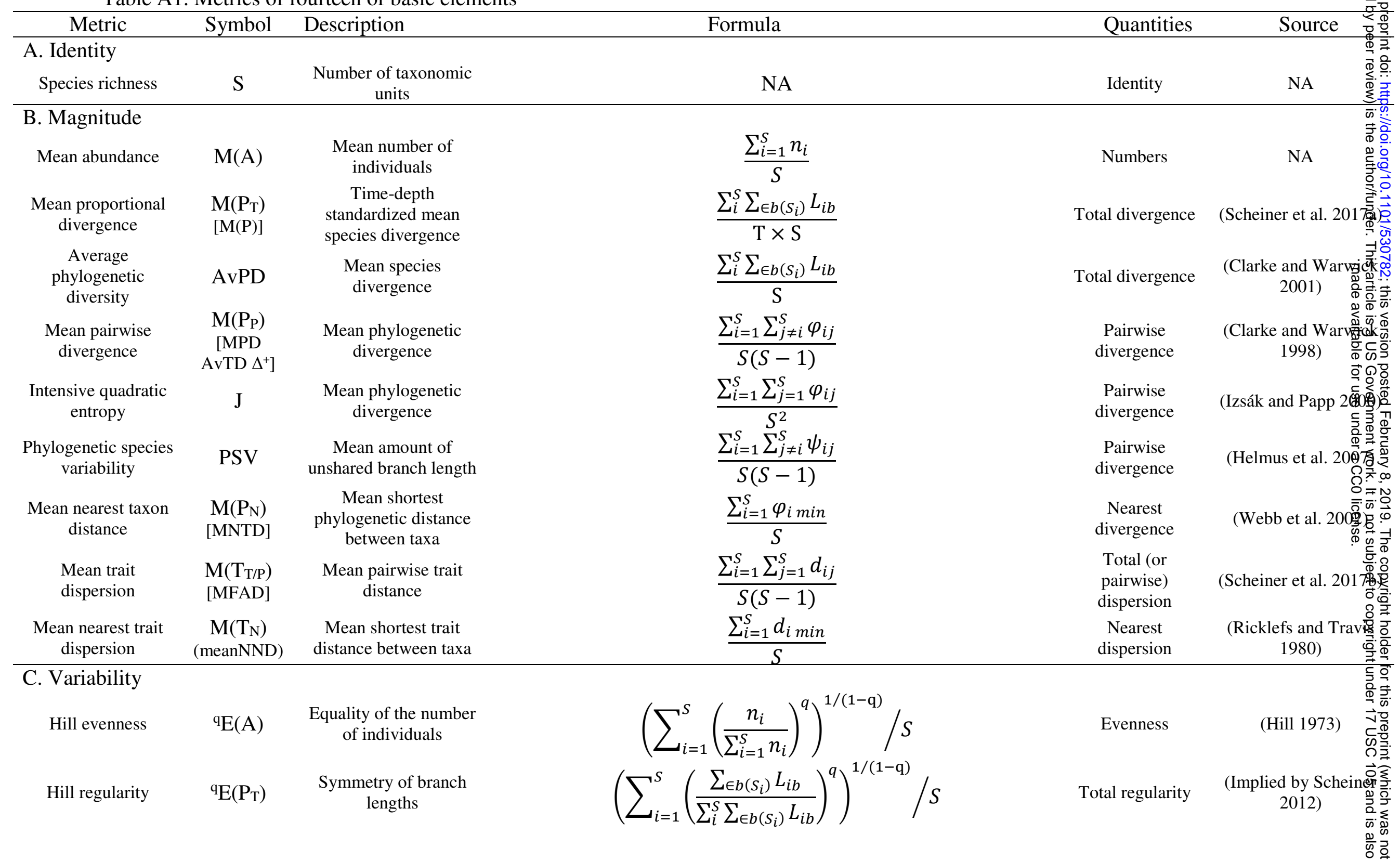




\begin{tabular}{|c|c|c|c|c|c|}
\hline $\mathrm{CV}$ of regularity & $\mathrm{C}\left(\mathrm{P}_{\mathrm{T}}\right)$ & $\begin{array}{l}\text { Coefficient of variation } \\
\text { of branch lengths }\end{array}$ & $\left(\sum_{i=1}^{S}\left(\sum_{\in b\left(S_{i}\right)} L_{i b}-\frac{\sum_{\in b\left(S_{i}\right)} L_{i b}}{S}\right)^{2}\right) /(\mathrm{S}-1) / \frac{\sum_{i}^{S} \sum_{\in b\left(S_{i}\right)} L}{\mathrm{~S}}$ & Total regularity & This paper \\
\hline $\begin{array}{l}\text { Hill pairwise } \\
\text { regularity }\end{array}$ & ${ }^{\mathrm{q}} \mathrm{E}\left(\mathrm{P}_{\mathrm{P}}\right)$ & $\begin{array}{l}\text { Evenness in pairwise } \\
\text { phylogenetic divergence }\end{array}$ & $\left(1+\sqrt{1+4}\left(\sum_{i=1}^{S} \sum_{j=1}^{S}\left(\frac{\varphi_{i j}}{\sum_{i=1}^{S} \sum_{j=1}^{S} \varphi_{i j}}\right)^{q}\right)\right) / 2 S$ & $\begin{array}{l}\text { Pairwise } \\
\text { regularity }\end{array}$ & This paper \\
\hline $\begin{array}{l}\mathrm{CV} \text { of pairwise } \\
\text { distances }\end{array}$ & $\mathrm{C}\left(\mathrm{P}_{\mathrm{P}}\right)$ & $\begin{array}{l}\text { Coefficient of variation } \\
\text { of pairwise phylogenetic } \\
\text { divergence }\end{array}$ & $\sqrt{\sum_{i=1}^{S} \sum_{j \neq i}^{S}\left(\varphi_{i j}-\frac{\sum_{i=1}^{S} \sum_{j \neq i}^{S} \varphi_{i j}}{S(S-1)}\right)^{2} / S(S-1)} / \frac{\sum_{i=1}^{S} \sum_{j \neq i}^{S} \varphi}{S(S-1)}$ & $\begin{array}{l}\text { Pairwise } \\
\text { regularity }\end{array}$ & This paper \\
\hline $\begin{array}{l}\text { Nearest taxon Hill } \\
\text { regularity }\end{array}$ & ${ }^{\mathrm{q}} \mathrm{E}\left(\mathrm{P}_{\mathrm{N}}\right)$ & $\begin{array}{l}\text { Equality of the nearest } \\
\text { pairwise phylogenetic } \\
\text { divergence }\end{array}$ & $\sum_{i=1}^{S}\left(\frac{\varphi_{i \min }}{\sum_{i=1}^{S} \varphi_{i \min }}\right)$ & $\begin{array}{l}\text { Nearest } \\
\text { regularity }\end{array}$ & This paper \\
\hline $\begin{array}{l}\text { ZV of nearest taxon } \\
\text { distances }\end{array}$ & $\mathrm{C}\left(\mathrm{P}_{\mathrm{N}}\right)$ & $\begin{array}{l}\text { Coefficient of variation } \\
\text { of nearest pairwise } \\
\text { phylogenetic divergence }\end{array}$ & $\sqrt{\sum_{i=1}^{S}\left(\varphi_{i \min }-\frac{\sum_{i=1}^{S} \varphi_{i \min }}{S}\right)^{2} / S} / \frac{\sum_{i=1}^{S} \varphi_{i \min }}{S}$ & $\begin{array}{l}\text { Nearest } \\
\text { regularity }\end{array}$ & This paper \\
\hline Hill equability & ${ }^{\mathrm{q}} \mathrm{E}\left(\mathrm{T}_{\mathrm{T}}\right)$ & $\begin{array}{l}\text { Equality in mean trait } \\
\text { distance }\end{array}$ & $\left(\frac{d_{i}}{\sum_{i=1}^{S} d_{i}}\right)^{q}$ & Total equability & $\begin{array}{l}\text { (Implied by Presles } \\
\text { al. 2014) }\end{array}$ \\
\hline $\begin{array}{l}\text { Hill pairwise } \\
\text { equability }\end{array}$ & $\begin{array}{l}{ }^{\mathrm{q}} \mathrm{E}\left(\mathrm{T}_{\mathrm{P}}\right) \\
{\left[{ }^{\mathrm{q}} \mathrm{E}(\mathrm{T})\right]}\end{array}$ & $\begin{array}{c}\text { Equality in pairwise } \\
\text { distances }\end{array}$ & $\left(1+\sqrt{1+4}\left(\sum_{i=1}^{S} \sum_{j=1}^{S}\left(\frac{d_{i j}}{\sum_{i=1}^{S} \sum_{j=1}^{S} d_{i j}}\right)^{q}\right)^{1 /(1-q)}\right) / 2 S$ & $\begin{array}{l}\text { Pairwise } \\
\text { equability }\end{array}$ & (Scheiner et al. 20 \\
\hline $\begin{array}{l}\text { Hill nearest } \\
\text { equability }\end{array}$ & ${ }^{\mathrm{q}} \mathrm{E}\left(\mathrm{T}_{\mathrm{N}}\right)$ & $\begin{array}{l}\text { Equality in nearest } \\
\text { distances }\end{array}$ & $\left(\sum_{i=1}^{S}\left(\frac{d_{i \min }}{\sum_{i=1}^{S} d_{i \min }}\right)^{q}\right)^{1 /(1-\mathrm{q}}$ & $\begin{array}{l}\text { Nearest } \\
\text { equability }\end{array}$ & $\begin{array}{l}\text { (Implied by Scheî } \\
\text { 2012) }\end{array}$ \\
\hline $\begin{array}{c}\mathrm{CV} \text { of nearest } \\
\text { neighbor distance }\end{array}$ & $\mathrm{C}\left(\mathrm{T}_{\mathrm{N}}\right)$ & $\begin{array}{l}\text { Coefficient of variation } \\
\text { in nearest distances }\end{array}$ & $\sqrt{\sum_{i=1}^{S}\left(d_{i \min }-\frac{\sum_{i=1}^{S} d_{i \min }}{S}\right)^{2} /(\mathrm{S}-1) / \frac{\sum_{i=1}^{S} d_{i \min }}{S}}$ & $\begin{array}{l}\text { Nearest } \\
\text { equability }\end{array}$ & This paper \\
\hline $\begin{array}{l}\text { Evenness of nearest } \\
\text { neighbor distance }\end{array}$ & $\begin{array}{l}\text { FNEve } \\
\text { [evenNND] }\end{array}$ & $\begin{array}{l}\text { Equality in nearest } \\
\text { distances }\end{array}$ & $\left.\operatorname{nin}\left(\frac{d_{i \min }}{\sum_{i=1}^{S-1} d_{i \min }}, \frac{1}{S}\right)-\frac{1}{S}\right) /\left(1-\frac{1}{S}\right)$ & $\begin{array}{l}\text { Nearest } \\
\text { equability }\end{array}$ & (Weiher 2011) \\
\hline
\end{tabular}


Table A2. Metrics that combine species richness with one other basic element.

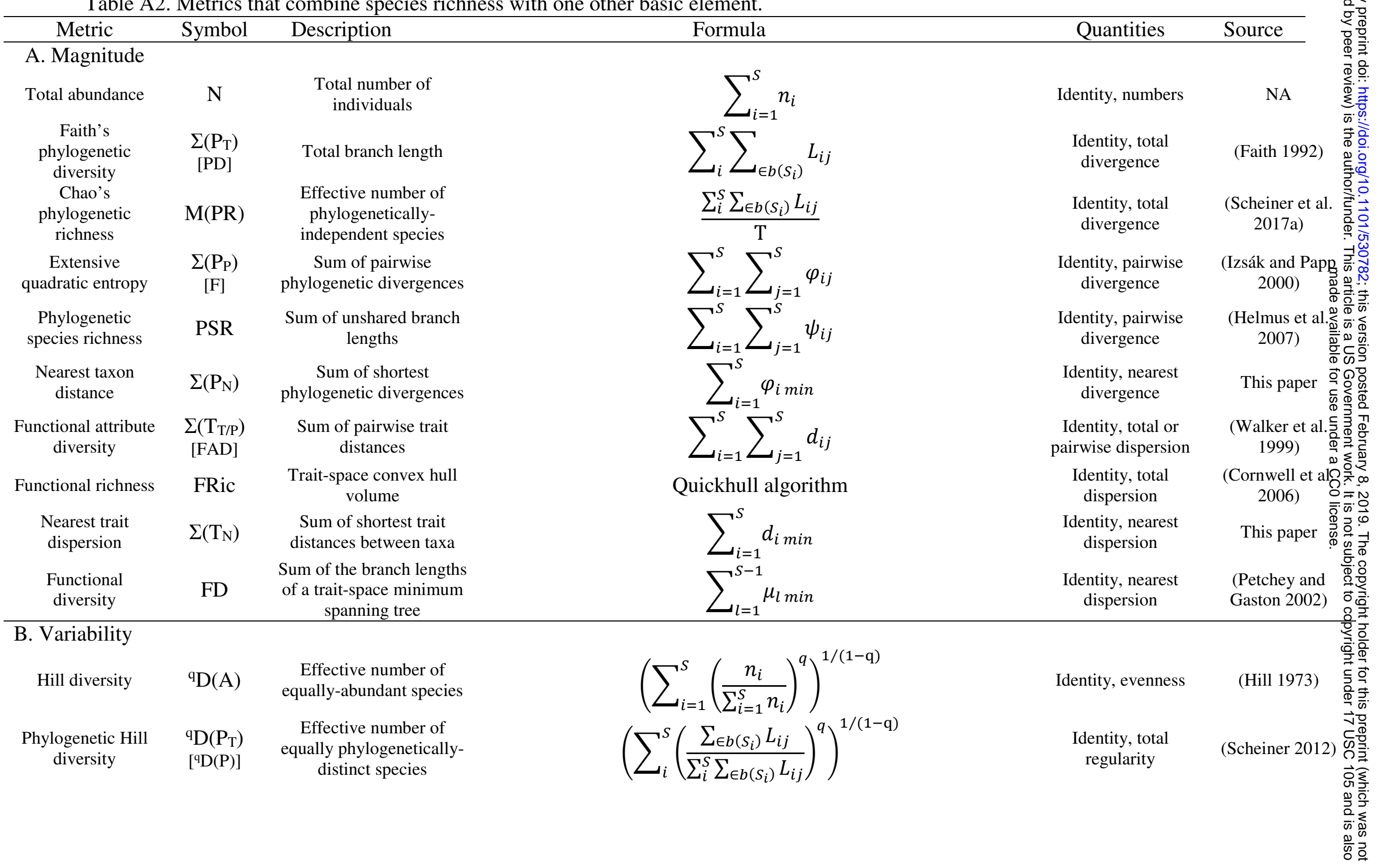


Pairwise

phylogenetic Hill

diversity

Nearest taxon Hill diversity

Functional-trait

Hill diversity

\section{Pairwise}

functional-trait Hill

diversity

Nearest functionaltrait Hill diversity
Effective number of equally phylogeneticallydistinct species

Effective number of equally phylogeneticallydistinct species

Effective number of

equally functionallydistinct species

\section{Effective number of} equally functionallydistinct species

[ $\left.{ }^{\mathrm{q}} \mathrm{D}(\mathrm{T})\right]$

${ }^{\mathrm{q}} \mathrm{D}\left(\mathrm{T}_{\mathrm{N}}\right)$ [ $\left.{ }^{\mathrm{q}} \mathrm{D}(\mathrm{F})\right]$

\section{Effective number of} distinct species

$$
\left(1+\sqrt{1+4\left(\sum_{i=1}^{S} \sum_{j=1}^{S}\left(\frac{\varphi_{i j}}{\sum_{i=1}^{S} \sum_{j=1}^{S} \varphi_{i j}}\right)^{q}\right)^{1 /(1-q)}}\right) / 2
$$

$$
\left(1+\sqrt{1+4\left(\sum_{i=1}^{S} \sum_{j=1}^{S}\left(\frac{d_{i j}}{\sum_{i=1}^{S} \sum_{j=1}^{S} d_{i j}}\right)^{q}\right)^{1 /(1-q)}}\right) / 2
$$$$
\left(\sum_{i=1}^{S}\left(\frac{\varphi_{i \min }}{\sum_{i=1}^{S} \varphi_{i \min }}\right)^{q}\right)^{1 /(1-\mathrm{q})}
$$$$
\left(\sum_{i=1}^{S}\left(\frac{d_{i}}{\sum_{i=1}^{S} d_{i}}\right)^{q}\right)^{1 /(}
$$

Identity, pairwise

Identity, pairwise

$$
\left(\sum_{i=1}^{S}\left(\frac{d_{i \min }}{\sum_{i=1}^{S} d_{i \min }}\right)^{q}\right)^{1 /(1-\mathrm{q})}
$$
equability regularity

Identity, nearest regularity

Identity, total equability

This paper

This paper

(Presley et al. 2014)

(Scheiner et al. 2017b)

Identity, nearest equability 
Table A3. Metrics that combine magnitude and variability of the same data type

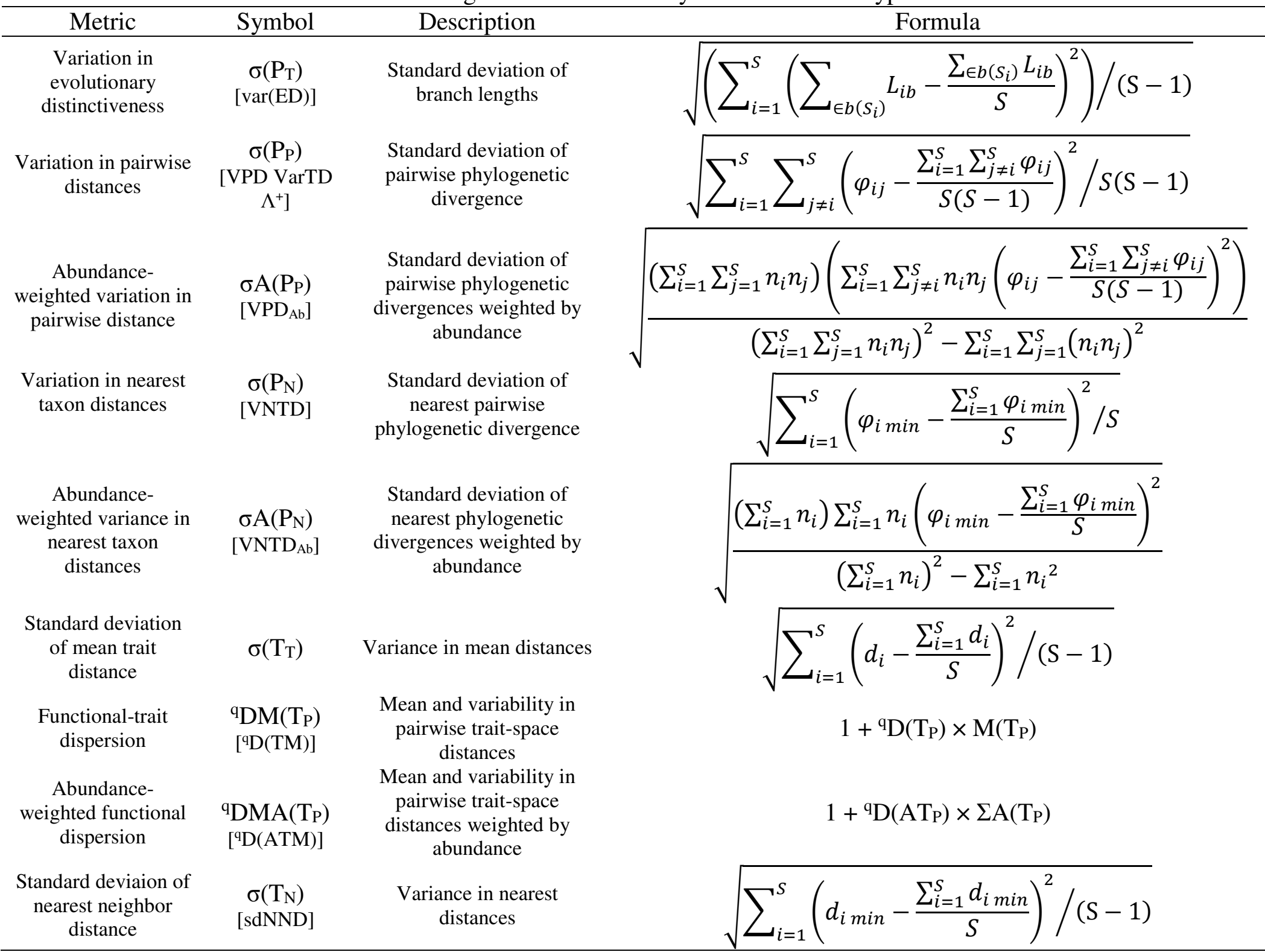

Total regularity

Pairwise

divergence, pairwise regularity

Numbers, pairwise divergence, pairwise regularity

Nearest divergence, nearest regularity

Numbers, nearest divergence, nearest regularity

Total dispersion, total equability

Identity, pairwise dispersion, pairwise equability

Identity, numbers, pairwise dispersion, pairwise equability

Nearest dispersion, nearest equability
Source-

(Implied b

Tucker et a 2017)

(Implied b

Clarke anc

Warwick

2001)

(Implied b

Tucker eţaks

2017)

(Implied w.

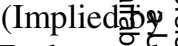

Tucker eচax

2017)응

(Impliedक्षे

Tucker ef̉a

2017)

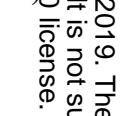

This pape

(Scheiner al. 2017b

(Scheiner al. 2017b) Travis 1989) 
Table A4. Metrics that combine abundance with one other basic element involving phylogeny or traits.

\begin{tabular}{|c|c|c|c|}
\hline Metric & Symbol & Description & Source \\
\hline $\begin{array}{l}\text { Abundance- } \\
\text { weighted mean } \\
\text { proportional } \\
\text { divergence }\end{array}$ & $\operatorname{MA}\left(\mathrm{P}_{\mathrm{T}}\right)$ & $\begin{array}{l}\text { Time-depth standardized } \\
\text { mean branch length } \\
\text { weighted by abundance }\end{array}$ & This paper \\
\hline $\begin{array}{l}\text { Abundance- } \\
\text { weighted average } \\
\text { phylogenetic } \\
\text { diversity }\end{array}$ & $\operatorname{avPD}_{A b}$ & $\begin{array}{c}\text { Mean branch length } \\
\text { weighted by abundance }\end{array}$ & $\begin{array}{c}\text { (Tucker et al. } \\
\text { 2017) }\end{array}$ \\
\hline $\begin{array}{l}\text { Abundance- } \\
\text { weighted mean } \\
\text { phylogenetic } \\
\text { diversity }\end{array}$ & $\mathrm{MA}\left(\mathrm{P}_{\mathrm{P}}\right)$ & $\begin{array}{l}\text { Mean pairwise } \\
\text { phylogenetic divergence } \\
\text { weighted by abundance }\end{array}$ & This paper \\
\hline $\begin{array}{l}\text { Abundance- } \\
\text { weighted mean } \\
\text { nearest taxon } \\
\text { distance }\end{array}$ & $\begin{array}{l}\operatorname{MA}\left(\mathrm{P}_{\mathrm{N}}\right) \\
{\left[\mathrm{MNTD}_{\mathrm{Ab}}\right]}\end{array}$ & $\begin{array}{c}\text { Abundance-weighted mean } \\
\text { shortest phylogenetic } \\
\text { divergence }\end{array}$ & (Webb et al \\
\hline $\begin{array}{l}\text { Phylogenetic- } \\
\text { weighted Hill } \\
\text { evenness }\end{array}$ & ${ }^{\mathrm{q}} \mathrm{EP}_{\mathrm{T}}(\mathrm{A})$ & $\begin{array}{l}\text { Phylogenetically-weighted } \\
\text { equality of species } \\
\text { abundances }\end{array}$ & $\begin{array}{c}\text { (Implied bys } \\
\text { Chao et al. } \\
\text { 2010) }\end{array}$ \\
\hline $\begin{array}{l}\text { Pairwise } \\
\text { phylogenetic- } \\
\text { weighted Hill } \\
\text { evenness }\end{array}$ & ${ }^{\mathrm{q}} \mathrm{EP}_{\mathrm{P}}(\mathrm{A})$ & $\begin{array}{l}\text { Pairwise phylogenetically- } \\
\text { weighted equality of } \\
\text { species abundances }\end{array}$ & This paper \\
\hline $\begin{array}{l}\text { Phylogenetic- } \\
\text { weighted Hill } \\
\text { evenness }\end{array}$ & ${ }^{\mathrm{q}} \mathrm{EP}_{\mathrm{N}}(\mathrm{A})$ & $\begin{array}{c}\text { Phylogenetically-weighted } \\
\text { equality of species } \\
\text { abundances }\end{array}$ & This paper \\
\hline $\begin{array}{l}\text { Abundance- } \\
\text { weighted mean trait } \\
\text { distance }\end{array}$ & $\operatorname{MA}\left(\mathrm{T}_{\mathrm{T}}\right)$ & $\begin{array}{c}\text { Mean trait distance } \\
\text { weighted by abundance }\end{array}$ & This paper \\
\hline $\begin{array}{l}\text { Abundance- } \\
\text { weighted mean trait } \\
\text { distance }\end{array}$ & $\begin{array}{l}\mathrm{M}_{\mathrm{I}}\left(\mathrm{T}_{\mathrm{T}}\right) \\
{\left[\mathrm{M}_{\mathrm{I}}(\mathrm{T})\right]}\end{array}$ & $\begin{array}{l}\text { Mean trait distance } \\
\text { between all individuals } \\
\text { ignoring species identity }\end{array}$ & $\begin{array}{l}\text { (Scheiner et } \\
\text { al. 2017b) }\end{array}$ \\
\hline Functional distance & FDis & $\begin{array}{c}\text { Mean distance from the } \\
\text { centroid weighted by } \\
\text { abundance }\end{array}$ & $\begin{array}{l}\text { (Laliberté and } \\
\text { Legendre } \\
\text { 2010) }\end{array}$ \\
\hline
\end{tabular}


Abundanceweighted mean functional

dispersion

Abundance-

weighted nearest

trait distance

Trait-weighted Hill evenness

Mean functional diversity

Trait-weighted Hill evenness

Trait-weighted Hill evenness

Phylogeneticweighted abundance

\section{Abundance-} weighted

phylogenetic Hill evenness

Abundanceweighted

phylogenetic Hill evenness

Abundanceweighted

phylogenetic Hill evenness

Abundanceweighted

phylogenetic Hill evenness
Mean pairwise trait-space distance weighted by abundance

Mean shortest trait distance weighted by abundance

Trait-weighted equality abundant species

Effective sum of pairwise distances

$\left[{ }^{\mathrm{q}} \mathrm{MD}(\mathrm{Q})\right]$

qFE(Q) Trait-weighted equality of species abundances

${ }^{\mathrm{q}} \mathrm{ET}_{\mathrm{N}}(\mathrm{A})$

Trait-weighted equality abundant species

$\mathrm{MP}_{\mathrm{T}}(\mathrm{A}) \quad$ Phylogenetically-weighted $[\mathrm{A}(\mathrm{P})]$

effective mean abundance

${ }^{\mathrm{q}} \mathrm{E}_{\mathrm{I}} \mathrm{A}\left(\mathrm{P}_{\mathrm{T}}\right)$

$\left[{ }^{\mathrm{q}} \mathrm{E}_{\mathrm{I}}(\mathrm{AP})\right]$

Symmetry of branch lengths weighted by abundance

Number of equally

${ }^{\mathrm{q}} \mathrm{EA}\left(\mathrm{P}_{\mathrm{T}}\right)$ divergent species weighted by abundance

Equality of pairwise divergences weighted by abundance

$$
\frac{\sum_{i=1}^{S} \sum_{j=1}^{S} d_{i j} n_{i} n_{j}}{S(S-1) N^{2}}
$$

$\left(\sum_{i=1}^{S} \sum_{j=1}^{S} d_{i j}\left(\frac{n_{i} n_{j}}{\sum_{i=1}^{S} \sum_{j=1}^{S} d_{i j} n_{i} n_{j}}\right)^{q}\right)^{1 /(1-q)} / S$

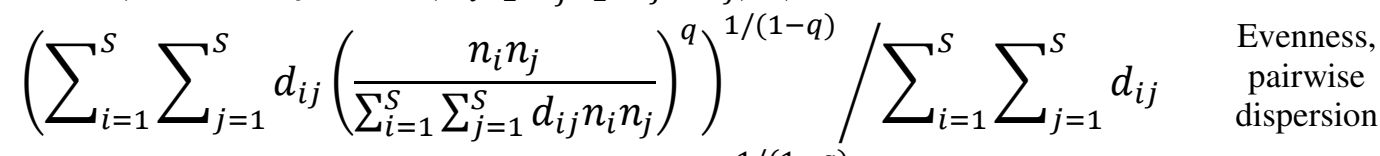

$$
\left(\sum_{i=1}^{S} d_{i \min }\left(\frac{n_{i}}{\sum_{i=1}^{S} d_{i \min } n_{i}}\right)^{q}\right)^{1 /(1-q)} / S
$$$$
\sum_{i}^{S} n_{i} /\left(\sum_{i}^{S}\left(\frac{\sum_{\in b\left(S_{i}\right)} n_{i} L_{j} / N_{j}}{\sum_{i}^{S} \sum_{\in b\left(S_{i}\right)} n_{i} L_{j} / N_{j}}\right)^{q}\right)^{1 /(1}
$$

$$
\left(\sum_{i}^{S}\left(\frac{\sum_{\in b\left(S_{i}\right)} n_{i} L_{b} / N_{j}}{\sum_{i}^{S} \sum_{\in b\left(S_{i}\right)} n_{i} L_{b} / N_{j}}\right)^{q}\right)^{1 /(1-\mathrm{q})} / \mathrm{S}
$$

${ }^{\mathrm{q}} \mathrm{EA}\left(\mathrm{P}_{\mathrm{P}}\right)$

Equality of nearest

${ }^{\mathrm{q}} \mathrm{EA}\left(\mathrm{T}_{\mathrm{N}}\right)$

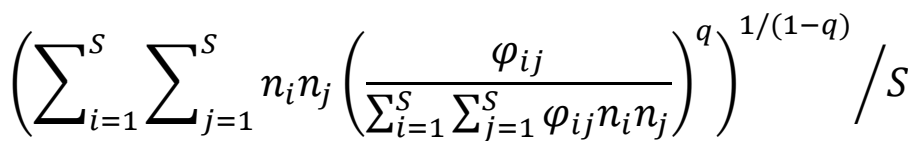

Numbers, pairwise regularity

Numbers, nearest regularity hylogenetic divergences weighted by abundance$$
\frac{\sum_{i=1}^{S} d_{i \min } n_{i}}{S N}
$$

$$
\left(\sum_{i=1}^{S} d_{i}\left(\frac{n_{i}}{\sum_{i=1}^{S} d_{i} n_{i}}\right)^{q}\right)^{1 /(1-q)} / S
$$

Evenness, pairwise dispersion

Evenness, nearest dispersion

Numbers, total regularity

Numbers, total regularity

$$
\left(\sum_{i=1}^{S} n_{i}\left(\frac{L_{i}}{\sum_{i=1}^{S} L_{i} n_{i}}\right)^{q}\right)^{1 /(1-q)} / S
$$

Numbers, total equability

This paper

(Weiher

This paper

(Chiu and $\Phi$

Chao 2014)

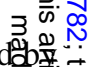

Chiu $\frac{\pi}{5} \frac{5}{0}$

Chao $20 \pm \bar{s}$

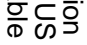

This paper $\stackrel{\overrightarrow{0}}{\Omega}, \overrightarrow{0}$

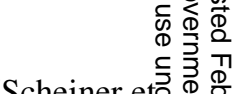

al. 2017a)

(Scheiner et⿳亠二口犬

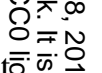
al. 2017a) $\underset{\varnothing}{\stackrel{\Phi}{~}}$ Ф 동 궁

This paper

$$
\left(\sum_{i=1}^{S} n_{i}\left(\frac{\varphi_{i \min }}{\sum_{i=1}^{S} \varphi_{i \min } n_{i}}\right)^{q}\right)^{1 /(1-q)} / S
$$

This paper 
Phylogenetic evenness

Abundance and phylogenetic Hill evenness

Abundanceweighted Hill pairwise regularity

Abundanceweighted pairwise phylogenetic Hill evenness

Abundance and phylogenetic Hill evenness

Trait-weighted abundance

Abundanceweighted functional Hill evenness

\section{Functional}

divergence

Abundanceweighted functional

Hill evenness

Abundance-

weighted functional Hill evenness
Equality in the branch lengths of a phylogenetic minimal-spanning tree weighted by abundance

\section{Equality of abundances} and phylogenetic divergences

Equality of pairwise

${ }^{\mathrm{q}} \mathrm{E}_{\mathrm{I}}(\mathrm{AP} \mathrm{P})$ divergences weighted by equality of abundances

${ }^{\mathrm{q}} \mathrm{E}\left(\mathrm{AP} \mathrm{P}_{\mathrm{P}}\right)$

Equality in abundances and pairwise divergences

Equality in abundances and nearest phylogenetic divergences

Trait-weighted effective mean abundance

Number of equally distinct species weighted by abundance

Deviance from the centroid of the trait-space convex hull weighted by abundance

$\left[\sum_{l=1}^{S-1} \min \left(\frac{\frac{\varphi_{l \min }}{\left(n_{i}+n_{j}\right) / N}}{\sum_{l=1}^{S-1} \frac{\varphi_{l \min }}{\left(n_{i}+n_{j}\right) / N}}, \frac{1}{S-1}\right)-\frac{1}{S-1}\right] /\left[1-\frac{1}{S-1}\right] / \begin{gathered}\text { Numbers, } \\ \text { nearest } \\ \text { regularity }\end{gathered}$ $\left(\sum_{i}^{s}\left(\frac{n_{i} L_{i}}{\Sigma n_{i} L_{i}}\right)^{q}\right)^{1 / 1-q} / S$

$\underline{\left(1+\sqrt{1+4\left(\sum_{i=1}^{S} \sum_{j=1}^{S}\left(\frac{\varphi_{i j}}{\sum_{i=1}^{S} \sum_{j=1}^{S} \varphi_{i j}}\right)^{q}\right)^{1 /(1-q)}}\right)}$ $2 N S /\left(\sum_{i=1}^{S}\left(\frac{n_{i}}{N}\right)^{q}\right)$

$\left(1+\sqrt{1+4\left(\sum_{i=1}^{S} \sum_{j=1}^{S}\left(\frac{\varphi_{i j} n_{i} n_{j}}{\sum_{i=1}^{S} \sum_{j=1}^{S} \varphi_{i j} n_{i} n_{j}}\right)^{q}\right)^{1 /(1-q)}}\right) / 2 S$ $\left(\sum_{i}^{s}\left(\frac{n_{i} \varphi_{i \min }}{\Sigma n_{i} \varphi_{i \min }}\right)^{q}\right)^{1 / 1-q} / S$ $\sum_{i}^{S} n_{i} /\left(\sum_{i}^{S}\left(\frac{n_{i} d_{i}}{\sum_{i=1}^{S} n_{i} d_{i}}\right)^{q}\right)^{1 /(1-\mathrm{q})}$ $\left(\sum_{i=1}^{S} n_{i}\left(\frac{d_{i}}{\sum_{i=1}^{S} d_{i} n_{i}}\right)^{q}\right)^{1 /(1-q)} / S$

$$
\frac{\Delta d+\overline{d G}}{\Delta|d|+\overline{d G}}
$$

$$
\left(\sum_{i=1}^{S} \sum_{j=1}^{S} n_{i} n_{j}\left(\frac{d_{i j}}{\sum_{i=1}^{S} \sum_{j=1}^{S} d_{i j} n_{i} n_{j}}\right)^{q}\right)^{1 /(1-q)} / S
$$$$
\left(\sum_{i=1}^{S} n_{i}\left(\frac{d_{i \min }}{\sum_{i=1}^{S} d_{i \min } n_{i}}\right)^{q}\right)^{1 /(1-q)} / S
$$

Evenness, total regularity

Evenness, pairwise regularity

Evenness, pairwise regularity

Evenness, nearest regularity

Numbers, total equability

Numbers, total equability equally distinct species weighted by abundance

Number of equally distinct species weighted by abundance
${ }^{\mathrm{q}} \mathrm{EA}\left(\mathrm{T}_{\mathrm{N}}\right)$ 
Functional evenness

FEve

Functional Hill evenness

Phylogenetic and functional Hill evenness

\section{Abundance- weighted Hill pairwise trait} evenness

Abundanceweighted functionaltrait Hill evenness

Nearest functionaltrait Hill evenness

Phylogenetic and nearest functionaltrait Hill evenness
Equality in distances of a trait-space minimalspanning tree weighted by abundance

${ }^{\mathrm{q}} \mathrm{E}\left(\mathrm{AT}_{\mathrm{T}}\right) \quad$ Equality of abundances and trait-space distances

Equality of abundances,

${ }^{\mathrm{q}} \mathrm{E}\left(\mathrm{AP}_{\mathrm{T}} \mathrm{T}_{\mathrm{T}}\right)$ phylogenetic divergences, and trait-space distances

${ }^{\mathrm{q}} \mathrm{E}_{\mathrm{I}}\left(\mathrm{AT} \mathrm{T}_{\mathrm{P}}\right)$

$\left[{ }^{\mathrm{q}} \mathrm{E}_{\mathrm{I}}(\mathrm{T})\right]$

${ }^{\mathrm{q}} \mathrm{E}\left(\mathrm{AT} \mathrm{T}_{\mathrm{P}}\right)$

[ $\left.{ }^{\mathrm{q}} \mathrm{E}(\mathrm{AT})\right]$

${ }^{\mathrm{q}} \mathrm{E}\left(\mathrm{AT} \mathrm{T}_{\mathrm{N}}\right)$

Equality in pairwise traitspace distances weighted by equality of abundances

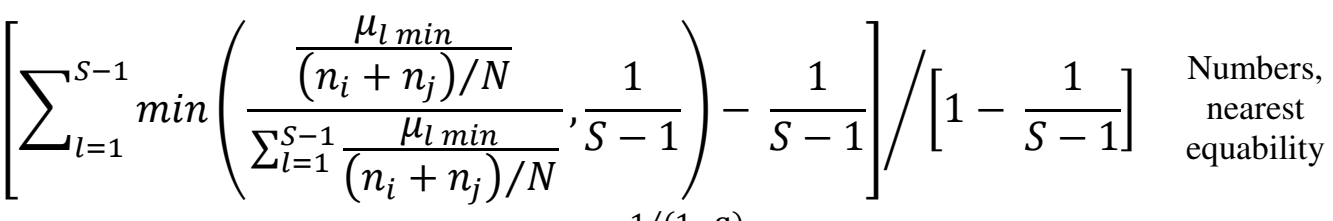

$$
\left(\sum_{i=1}^{S}\left(\frac{n_{i} d_{i}}{\sum_{i=1}^{S} n_{i} d_{i}}\right)^{q}\right)^{1 /(1-\mathrm{q})} / S
$$$$
\left(\sum_{i=1}^{S}\left(\frac{n_{i} L_{i} d_{i}}{\sum_{i=1}^{S} n_{i} L_{i} d_{i}}\right)^{q}\right)^{1 /(1-\mathrm{q})} / S
$$
regularity, total

$$
\frac{\left(1+\sqrt{1+4\left(\sum_{k=1}^{S} \sum_{l=1}^{S}\left(\frac{d_{k l}}{\sum_{k}^{N} \sum_{l}^{N} d_{k l}}\right)^{q}\right)^{1 /(1-q)}}\right)}{2 N S /\left(\sum_{i=1}^{S}\left(\frac{n_{i}}{N}\right)^{q}\right)^{1 /(1-\mathrm{q})}}
$$

Equality in pairwise traitspace distances weighted

$$
\text { by abundance }
$$

$$
\left(1+\sqrt{1+4\left(\sum_{i=1}^{S} \sum_{j=1}^{S}\left(\frac{d_{i j} n_{i} n_{j}}{\sum_{i=1}^{S} \sum_{j=1}^{S} d_{i j} n_{i} n_{j}}\right)^{q}\right)^{1 /(1-q)}}\right) / 2 S
$$

Equality in abundances and nearest trait-space distances

$$
\left(\sum_{i=1}^{S}\left(\frac{n_{i} d_{i \min }}{\sum_{i=1}^{S} n_{i} d_{i \min }}\right)^{q}\right)^{1 /(1-\mathrm{q})} / S
$$

Equality in abundances,

${ }^{\mathrm{q}} \mathrm{E}\left(\mathrm{AP}_{\mathrm{T}} \mathrm{T}_{\mathrm{N}}\right)$ phylogenetic divergences, and nearest trait-space regularity, nearest distances

$$
\left(\sum_{i=1}^{S}\left(\frac{n_{i} L_{i} d_{i \min }}{\sum_{i=1}^{S} n_{i} L_{i} d_{i \min }}\right)^{q}\right)^{1 /(1-\mathrm{q})} / S
$$

Evenness, total equability

Evenness, total equability

\section{Evenness,} pairwise equability

(Villéger et al. 2008)

This paper

This paper

Evenness, pairwise equability

Evenness, nearest equability

Evenness, total equability
(Scheiner et al. 2017b)

Scheiner al. 2017b)

(Implied by Scheiner 2012)

(Implied by Scheiner 2012) 
Table A5. Metrics that combine species richness and abundance with one or more other basic elements involving phylogeny or traits.

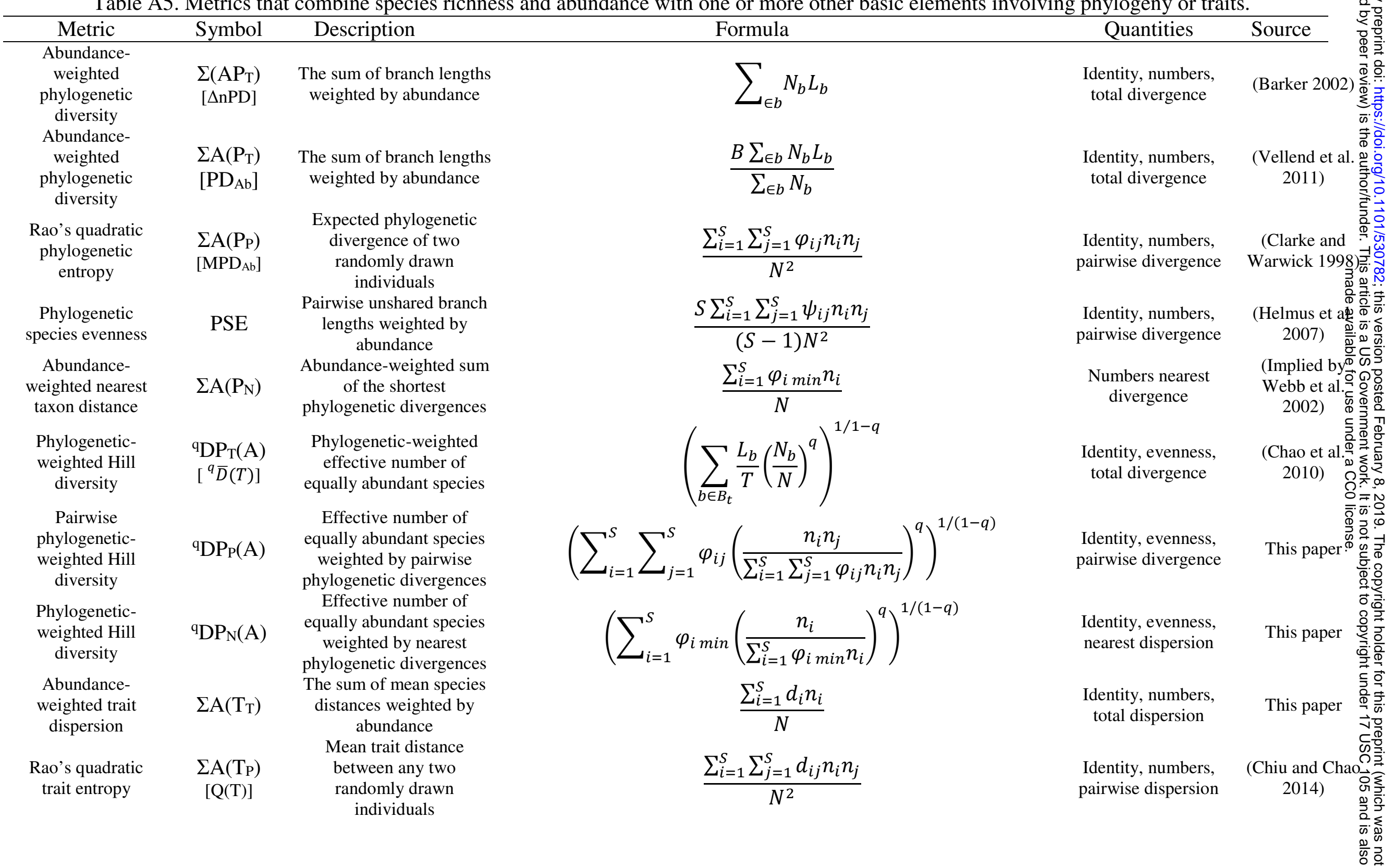


Abundanceweighted nearest

trait distance

Trait-weighted Hill diversity

Trait-weighted Hill diversity

Trait-weighted Hill diversity

Abundanceweighted

phylogenetic Hill diversity

Abundanceweighted

phylogenetic Hill diversity

Abundance-

weighted

phylogenetic Hill

diversity

Abundance-

weighted functional Hill diversity

Abundance and phylogenetic Hill diversity

$\sum \mathrm{A}\left(\mathrm{T}_{\mathrm{N}}\right)$

${ }^{\mathrm{qDT}} \mathrm{T}(\mathrm{A})$

${ }^{\mathrm{q}} \mathrm{DT}_{\mathrm{P}}(\mathrm{A})$

[ $\mathrm{FD}(\mathrm{Q})]$

${ }^{\mathrm{q}} \mathrm{DT}_{\mathrm{N}}(\mathrm{A})$

${ }^{\mathrm{q}} \mathrm{D}_{\mathrm{I}} \mathrm{A}\left(\mathrm{P}_{\mathrm{T}}\right)$

[ $\left.{ }^{\mathrm{q}} \mathrm{D}_{\mathrm{I}}(\mathrm{AP})\right]$

${ }^{\mathrm{q}} \mathrm{DA}\left(\mathrm{P}_{\mathrm{T}}\right)$

${ }^{\mathrm{q}} \mathrm{DA}\left(\mathrm{P}_{\mathrm{P}}\right)$

${ }^{\mathrm{q}} \mathrm{DA}\left(\mathrm{P}_{\mathrm{N}}\right)$

${ }^{\mathrm{q}} \mathrm{D}\left(\mathrm{AP}_{\mathrm{T}}\right)$

[ $\left.{ }^{\mathrm{D}}(\mathrm{AP})\right]$

Abundance-

weighted

phylogenetic Hill

diversity

${ }^{\mathrm{q}} \mathrm{D}_{\mathrm{I}}(\mathrm{AP} \mathrm{P})$
Mean shortest trait

distance weighted by abundance

Trait-weighted effective number of equally abundant species

Trait-weighted effective number of equally abundant species

Trait-weighted effective number of equally abundant species

Effective number of phylogenetically-distinct species weighted by abundance

Effective number of equally divergent species weighted by abundance

Effective number of equally divergent species

Effective number of equally distinct species weighted by abundance Effective number of equally abundant and phylogenetically distinct species

Effective number of phylogenetically-distinct species weighted by the effective abundance weighted by abundance

$$
\begin{aligned}
& \frac{\sum_{i=1}^{S} d_{i \min } n_{i}}{N} \\
& \left(\sum_{i=1}^{S} d_{i}\left(\frac{n_{i}}{\sum_{i=1}^{S} d_{i} n_{i}}\right)^{q}\right)^{1 /(1-q)} \\
& \left(\sum_{i=1}^{S} \sum_{j=1}^{S} d_{i j}\left(\frac{n_{i} n_{j}}{\sum_{i=1}^{S} \sum_{j=1}^{S} d_{i j} n_{i} n_{j}}\right)^{q}\right)^{1 /(1-q)} \\
& \left(\sum_{i=1}^{S} d_{i \min }\left(\frac{n_{i}}{\sum_{i=1}^{S} d_{i \min } n_{i}}\right)^{q}\right)^{1 /(1-q)} \\
& \left(\sum_{i}^{S}\left(\frac{\sum_{\in b\left(S_{i}\right)} n_{i} L_{b} / N_{b}}{\sum_{i}^{S} \sum_{\in b\left(S_{i}\right)} n_{i} L_{b} / N_{b}}\right)^{q}\right)^{1 /(1-\mathrm{q})} \\
& \left(\sum_{i=1}^{S} n_{i}\left(\frac{L_{i}}{\sum_{i=1}^{S} L_{i} n_{i}}\right)^{q}\right)^{1 /(1-q)} \\
& \left(\sum_{i=1}^{S} \sum_{j=1}^{S} n_{i} n_{j}\left(\frac{\varphi_{i j}}{\sum_{i=1}^{S} \sum_{j=1}^{S} \varphi_{i j} n_{i} n_{j}}\right)^{q}\right)^{1 /(1-q)} \\
& \left(\sum_{i=1}^{S} n_{i}\left(\frac{\varphi_{i \min }}{\sum_{i=1}^{S} \varphi_{i \min } n_{i}}\right)^{q}\right)^{1 /(1-q)} \\
& \left(\sum_{i}^{s}\left(\frac{n_{i} L_{i}}{\Sigma n_{i} L_{i}}\right)^{q}\right)^{1 / 1-q} \\
& \left(1+\sqrt{1+4\left(\sum_{i=1}^{S} \sum_{j=1}^{S}\left(\frac{\varphi_{i j}}{\sum_{i=1}^{S} \sum_{j=1}^{S} \varphi_{i j}}\right)^{q}\right)^{1 /(1-q)}}\right) \\
& 2 N /\left(\sum_{i=1}^{S}\left(\frac{n_{i}}{N}\right)^{q}\right)^{1 /(}
\end{aligned}
$$

Identity, numbers, nearest dispersion

Identity, evenness, total dispersion

Identity, evenness, pairwise dispersion

Identity, evenness, nearest dispersion

Identity, numbers, total regularity

Identity, numbers, total regularity

Identity, numbers, pairwise regularity

Identity, numbers, nearest regularity

Identity, evenness, total regularity

Identity, numbers, pairwise regularity
(Implied by

Weiher 2011)

This paper

Chiu and Chao 2014)

This paper

Scheiner 2010

This paper

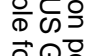

$\overrightarrow{\mathrm{O}} \mathrm{O}$, 
Abundance-

weighted pairwise phylogenetic Hill diversity

Abundance and nearest taxon Hill diversity

Abundanceweighted functional Hill diversity

Abundanceweighted functional Hill diversity

Abundanceweighted functional Hill diversity

Abundance and functional Hill diversity

Abundance, phylogenetic and functional Hill diversity

Abundanceweighted Hill pairwise trait diversity

Abundanceweighted functional Hill diversity
${ }^{\mathrm{q}} \mathrm{D}(\mathrm{APP})$

Effective number of equally abundant and phylogenetically distinct species

Effective number of equally abundant and

${ }^{\mathrm{q}} \mathrm{D}\left(\mathrm{AP} \mathrm{P}_{\mathrm{N}}\right)$ phylogenetically distinct species

Effective number of ${ }^{\mathrm{q}} \mathrm{DA}\left(\mathrm{T}_{\mathrm{T}}\right) \quad$ equally distinct species weighted by abundance

Effective number of equally distinct species weighted by abundance

Number of equally

${ }^{\mathrm{q}} \mathrm{DA}\left(\mathrm{T}_{\mathrm{N}}\right) \quad$ distinct species weighted

by abundance

Effective number of equally abundant and functionally distinct species

Effective number of equally abundant,

${ }^{\mathrm{q}} \mathrm{D}\left(\mathrm{AP}_{\mathrm{T}} \mathrm{T}_{\mathrm{T}}\right)$ phylogenetically distinct and functionally distinct species

Effective number of ${ }^{\mathrm{q}} \mathrm{D}_{\mathrm{I}}\left(\mathrm{AT}_{\mathrm{P}}\right)$ functionally distinct $\left[{ }^{\mathrm{q}} \mathrm{D}_{\mathrm{I}}(\mathrm{T})\right]$ ppecies weighted by the effective abundance

Variability in pairwise distances weighted by abundance
${ }^{\mathrm{q}} \mathrm{D}\left(\mathrm{AT} \mathrm{T}_{\mathrm{P}}\right)$

[ $\left.{ }^{\mathrm{D}} \mathrm{D}(\mathrm{AT})\right]$

$$
\left(1+\sqrt{1+4\left(\sum_{i=1}^{S} \sum_{j=1}^{S}\left(\frac{\varphi_{i j} n_{i} n_{j}}{\sum_{i=1}^{S} \sum_{j=1}^{S} \varphi_{i j} n_{i} n_{j}}\right)^{q}\right)^{1 /(1-q)}}\right) / 2
$$$$
\left(\sum_{i=1}^{S}\left(\frac{n_{i} \varphi_{i \min }}{\sum_{i=1}^{S} n_{i} \varphi_{i \min }}\right)^{q}\right)^{1 /(1-\mathrm{q})}
$$

$$
\left(\sum_{i=1}^{S} n_{i}\left(\frac{d_{i}}{\sum_{i=1}^{S} d_{i} n_{i}}\right)^{q}\right)^{1 /(1-q)}
$$

$$
\left(\sum_{i=1}^{S} \sum_{j=1}^{S} n_{i} n_{j}\left(\frac{d_{i j}}{\sum_{i=1}^{S} \sum_{j=1}^{S} d_{i j} n_{i} n_{j}}\right)^{q}\right)^{1 /(1-q)}
$$$$
\left(\sum_{i=1}^{S} n_{i}\left(\frac{d_{i \min }}{\sum_{i=1}^{S} d_{i \min } n_{i}}\right)^{q}\right)
$$$$
\left(\sum_{i=1}^{S}\left(\frac{n_{i} d_{i}}{\sum_{i=1}^{S} n_{i} d_{i}}\right)^{q}\right)^{1 /(1-\mathrm{q})}
$$

$$
\left(\sum_{i=1}^{S}\left(\frac{n_{i} L_{i} d_{i}}{\sum_{i=1}^{S} n_{i} L_{i} d_{i}}\right)^{q}\right)^{1 /(1-\mathrm{q})}
$$

$$
\frac{\left(1+\sqrt{1+4\left(\sum_{k=1}^{S} \sum_{l=1}^{S}\left(\frac{d_{k l}}{\sum_{k}^{N} \sum_{l}^{N} d_{k l}}\right)^{q}\right)^{1 /(1-q)}}\right)}{2 N /\left(\sum_{i=1}^{S}\left(\frac{n_{i}}{N}\right)^{q}\right)^{1 /(1-q)}}
$$

Identity, evenness, pairwise regularity

Identity, evenness, nearest regularity

Identity, numbers, total equability

Identity, numbers, pairwise equability

Identity, numbers, nearest equability

Identity, evenness, total equability

Identity, evenness, total regularity, total equability

Identity, evenness, pairwise equability

Identity, $\left(1+\sqrt{1+4\left(\sum_{i=1}^{S} \sum_{j=1}^{S}\left(\frac{d_{i j} n_{i} n_{j}}{\sum_{i=1}^{S} \sum_{j=1}^{S} d_{i j} n_{i} n_{j}}\right)^{q}\right)^{1 /(1-q)}}\right) / 2$ numbers, pairwise equability
This papero

This paper

This paper

This paper

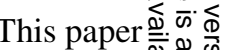

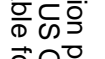

으 ᄋᄋㅇㅇ

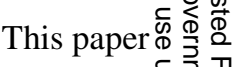

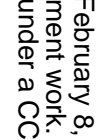

This paper $=0$

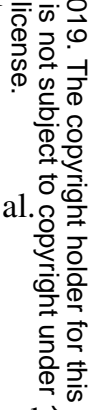

(Scheiner et al $\vec{\sim}$ 음 2017b)

cheiner et

$$
\text { 2017b) }
$$


Abundance and nearest functional Hill diversity

$$
{ }^{\mathrm{q}} \mathrm{D}\left(\mathrm{AT}_{\mathrm{N}}\right)
$$

Effective number of

equally abundant and

functionally distinct species

Effective number of

Abundance,

phylogenetic and nearest functional Hill diversity
${ }^{\mathrm{q}} \mathrm{D}\left(\mathrm{AP}^{\mathrm{T}} \mathrm{T}^{\mathrm{N}}\right) \quad \begin{gathered}\text { equally abundant, } \\ \text { phylogenetically distinct }\end{gathered}$

[ $\left.{ }^{\mathrm{q}} \mathrm{D}(\mathrm{APF})\right]$

and functionally distinct

$$
\left(\sum_{i=1}^{S}\left(\frac{n_{i} d_{i \min }}{\sum_{i=1}^{S} n_{i} d_{i \min }}\right)^{q}\right)^{1 /(1-\mathrm{q})}
$$

Identity, evenness, nearest equability

$$
\left(\sum_{i=1}^{S}\left(\frac{n_{i} L_{i} d_{i \min }}{\sum_{i=1}^{S} n_{i} L_{i} d_{i \min }}\right)^{q}\right)^{1 /(1-\mathrm{q})}
$$

Identity, evenness, total regularity, nearest equability
(Scheiner 2012

(Scheiner 2012) species 